\section{Australian Journal of Crop Science}

\title{
Losses in the mechanized harvesting of sugarcane as of speed function of two harvester models in Tropical Savanna Environment
}

\author{
Warlles D. Xavier ${ }^{1}$, Diogo C. Silva ${ }^{2}$, Rommel B. da Costa ${ }^{2}$, Diego O. Ribeiro ${ }^{1}$, Vinicius S. Sousa ${ }^{2}$, João Vitor \\ de S. Silva ${ }^{3}$
}

${ }^{1}$ Department of Soil, Federal Institute Goiano (IFGoiano), rod. Sul goiana, km 01, Countryside, Zip code 75901-970, Rio Verde, GO, Brazil

${ }^{2}$ Agriculture Sector, Agronomy School, Federal University of Goiás (EA-UFG), av. Esperança, sn, Zip code 74690-900, Goiânia, GO, Brazil

${ }^{3}$ Agronomist engineer, Market Development Consultant - Compass Minerals ${ }^{\bullet}$ Plant Nutrition. Zip code 47827-000, Roda Velho, BA, Brazil

*Corresponding author: warlles.pesquisa@gmail.com; ORCID 0000-0002-7016-5367

Abstract

The aim of this study was to evaluate the losses that occur in the sugarcane crop during the harvesting, based on the performance of two harvester models operated at different displacement speeds. The variety harvested was CTC4, with total productivity of 95.0 $\mathrm{Mg} \mathrm{ha}^{-1}$. The experimental design was completely randomized in a $2 \times 3$ factorial scheme with five replications. The treatments consisted of two harvester models (John Deere 3520 and John Deere CH570), operated in three different displacement speeds (3.0 $\mathrm{km} \mathrm{h}^{-1}, 4.0 \mathrm{~km} \mathrm{~h}^{-1}$ and $5.0 \mathrm{~km} \mathrm{~h}^{-1}$ ) in sugarcane harvesting. The quality indicators that assessed after sugarcane harvesting were the following loss types: stump cane, whole cane, tip cane, loose piece cane, shrapnel cane and total cane loss in Mg ha ${ }^{-1}$. The increase in displacement speed resulted in lower total losses in sugarcane harvesting. The 3520 harvester was superior to the $\mathrm{CH} 570$ at the highest speed tested. The reduction of sugarcane harvesting loss indexes was proportional to the increase of the displacement speeds for the parameters such as stump cane, whole cane, tip cane, loose piece cane and total loss cane for 3520 harvester and stump cane, whole cane and total loss cane for $\mathrm{CH} 570$ harvester, showing strong negative correlations $(>0.85)$.

Keywords: Loss of productivity, Saccharum officinarum, speed of harvesting, cane loose piece losses, John Deere harvester. Abbreviations: P_Phosphorus; K_Potassium; Ca_Calcium; Mg_Magnseium; S_Sulfur; CEC_Cation exchange capacity; CV_Coefficient

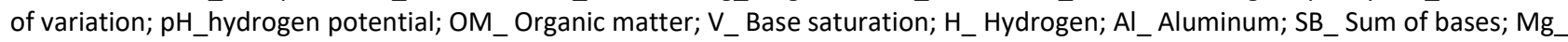
Megagrams; ha _ Hectare; km h_Kilometers per hour;

\section{Introduction}

Currently, Brazil is the world's leader in production of sugarcane (Saccharum officinarum L.), with a planted area of approximately 9.0 million hectares (Conab, 2018). This accelerated growth is due, among other factors, to biofuels, which present promising opportunities for a renewable, sustainable, affordable and efficient energy matrix (Pancelli et al., 2015). All this is combined with large cultivable areas and edaphoclimatic conditions favorable to mechanized harvesting, mainly in the Midwestern region of the country. By analyzing all the operations of the sugarcane production process, the harvesting stage can be considered as one of the most important and decisive factors for the competitiveness of the final production. This operation absorbs $30 \%$ of the total cost of the agricultural sector of a producing unit on average, with greater representativeness for the visible losses occurring in the form of material left in the field (Dias de Moraes, 2007).

Among the factors that influence the visible losses in the sugarcane harvesting, the harvester's displacement speed has been receiving special attention. Many scientific studies have already been carried out to evaluate the performance of sugarcane harvesters, both related to operational performance (Voltarelli et al., 2013; Salvi et al., 2007) and the losses of raw material generated from the displacement speed in the harvesting (Pelloso et al., 2019; Martins et al., 2017; Manhães et al., 2014; Neves et al., 2006).

Modern sugarcane harvesters have a capacity to operate at speeds of up to $9.0 \mathrm{~km} \mathrm{~h}^{-1}$. However, it is observed that these machines work best with a displacement speed of between 3.0 and $6.0 \mathrm{~km} \mathrm{~h}^{-1}$ (Ripoli and Ripoli, 2009). This possibly occurs due to the lack of systematization of plots for mechanized harvesting. In fields not suitable for mechanized harvesting, the use of higher speeds causes increased raw material losses. In order to increase the technical efficiency of sugarcane cultivation, it is important to fill the gaps related to reducing crop losses.

For the cultivation, the more specific studies are recent and with diverse results. Silva et al. (2015), worked with variety 
RB92579 and reported that the displacement speed $3.2 \mathrm{~km}$ $\mathrm{h}^{-1}$ is best indicated for sugarcane mechanized harvesting. For Rodrigues and Saab (2007), slow speeds in sugarcane harvesting can increase the cost, reducing the competitiveness of the sugarcane plant. Ripoli et al. (2001) and Carvalho Filho (2000) observed that the best operating capacity, economic performance, lowest visible losses and the highest purity index can be achieved at $5.4 \mathrm{~km} \mathrm{~h}^{-1}$ speed. However, the sugarcane mechanized harvesting still presents many losses, particularly in the process involving modern's cultivar of raw cane. Likewise, agriculture-related studies about monitoring sugarcane harvesting losses still are scarce, especially regarding displacement speed of modern's harvester in tropical savanna environment.

Thereby, it is necessary to propose and discuss viable alternatives that offer answers to the problems pointed out, contributing to the maintenance of sustainable competitiveness of the sugar-alcohol sector, especially in Brazil. Thus, the aim of this study was to evaluate the losses that occur in the sugarcane crop during the harvesting, based on the performance of two harvester models operated at different displacement speeds.

\section{Results and Discussion}

\section{Loss of plant material during sugarcane harvesting}

The technological characteristics of the crop in the harvesting showed satisfactory results (Table 1). According to Ripoli and Ripoli (2009), these maturation values of sugarcane are within the recommended quality standards of the harvested product.

The variable Sugarcane Stump Losses (SSL) showed a significant difference between the displacement speeds and the harvester models tested in the operation. The use of the 3520 harvester in the speed of $5.0 \mathrm{~km} \mathrm{~h}^{-1}$ provided the lowest loss value and the best performance among harvesters, with an average of $0.04 \mathrm{Mg} \mathrm{ha}^{-1}$ of SSL (Fig 1A).

In the basal cutting of the sugarcane harvesters, the operation at the lowest speed $\left(3.0 \mathrm{~km} \mathrm{~h}^{-1}\right)$ was associated with possible deficiency in cutting height control, causing the greatest loss of raw material, especially for the CH570 harvester that presented SSL of $0.29 \mathrm{Mg} \mathrm{ha}^{-1}$ (Maleki and Jamshidi, 2011). Such a situation generates a nonhomogeneous cut, leaving a high and fragmented stump, increasing the losses in the field and the probability of an attack of insects and diseases in the cane ratoon (Ripoli and Ripoli, 2009).

According to Peloia et al. (2010), the studies on mechanization promote operation improvements and reduce costs, since the use of low speeds may prevent the use of harvesters due to the reduced collection capacity and greater losses of the product in the field.

The results indicate that a shorter exposure time between the crop and the cutting deck of the harvester, due to the increase of displacement speed, was fundamental to reduce SSL and increasing the operational efficiency (Martins et al., 2019). The $\mathrm{CH} 570$ harvester also obtained the smaller SSL with the highest speed. However, the difference is $36.4 \%$ higher when compared to the 3520 harvester. Salvi (2006) analyzed a $275 \mathrm{~kW}$ power harvester with a displacement velocity of $4.23 \mathrm{~km} \mathrm{~h}^{-1}$, obtained a stump loss index of 0.05 $\mathrm{Mg} \mathrm{ha}^{-1}$, similar results to those found in this work.
These results show that, for the two evaluated harvester models, the greater efficiency in SSL reduction is linked to the higher displacement speed $\left(5.0 \mathrm{~km} \mathrm{~h}^{-1}\right)$, under the field conditions of the present study.

The displacement velocity of $5.0 \mathrm{~km} \mathrm{~h}^{-1}$ also had the lowest Sugarcane Whole Losses (SWL) for the two harvester models evaluated. The best performance was observed in the $\mathrm{CH} 570$ harvester that had $0.06 \mathrm{Mg} \mathrm{ha}^{-1}$ of SWL (Fig 1B).

In a study of the operational and economic performance of the mechanized harvesting, Carvalho Filho (2000) concluded that the harvester's displacement speed is one of the main factors that influenced the level of losses in the field. In this sense, the results of this study show that increase of harvester's displacement speed cause smaller SWL, greater amount of sugarcane harvested per unit area (data not measured). Consequently, the increase in the amount of harvested sugarcane declines the fuel cost per ton. Ripoli et al. (2001) observed that the $5.39 \mathrm{~km} \mathrm{~h}^{-1}$ is the ideal speed to obtain the best operational capacity.

Martins et al. (2017) observed that the average fuel consumption per ton of sugarcane was decreased with the increase of the speed. They verified a greater consumption of fuel in the speed of $2.5 \mathrm{~km} \mathrm{~h}^{-1}$ compared to the speed of $5.0 \mathrm{~km} \mathrm{~h}^{-1}$.

Analyzing the performance of the $\mathrm{CH} 570$ harvester, the 3.0 $\mathrm{km} \mathrm{h}^{-1}$ displacement speed provided a $90.8 \%$ increase in the SWL, when compared to the highest speed tested. In addition, the harvester's slow displacement speed can make the harvesting cost higher, thus reducing the competitiveness of agricultural activity (Rodrigues and Saab, 2007).

In the evaluations of Sugarcane Tip Losses (STL), the F-test also showed a significant difference depending on the displacement speed and the harvester model. For the 3520 harvester, no variation was obtained by increasing or reducing the displacement speed on the response variable. The $\mathrm{CH} 570$ harvester presented the best results at $4.0 \mathrm{~km} \mathrm{~h}^{-1}$ and $5.0 \mathrm{~km} \mathrm{~h}^{-1}$, with mean STL values of $0.18 \mathrm{Mg} \mathrm{h}^{-1}$ (Fig 2A).

Although it is not the part with the highest concentration of sucrose, STL can mean considerable losses in the total accumulated in the case of cane in full maturation. In this study, even with the lowest STL $\left(0.18 \mathrm{Mg} \mathrm{ha}^{-1}\right)$ at speeds greater than $3.0 \mathrm{~km} \mathrm{~h}^{-1}$, the observed losses represent $13.6 \%$ of the total losses of the $\mathrm{CH} 570$ harvester. These results corroborate with Furlani Neto et al. (1996) findings which reported percentage values between 9.12 and $14.09 \%$ of sugarcane tip losses.

These losses are those that remain in the field in the form of uncollected material. For Ripoli and Ripoli (2005), the ideal is that this index does not exceed $2 \%$ of total losses. Ripoli et al. (2001) studied the displacement speeds of a sugarcane harvester at 1.5, 3.0, 5.0 and $7.0 \mathrm{~km} \mathrm{~h}^{-1}$ and obtained values between 4.38 and $7.06 \%$ for this index. For Salvi (2006) the losses in the form of tip cane can be associated with a harvester topper disconnected or damaged, unevenness of the terrain and damping-off of the crop, where the sugarcane tip losses were not associated with the harvester's displacement speed. Regarding the Sugarcane Loose Piece Losses (SLPL), the speed of $5.0 \mathrm{~km} \mathrm{~h}^{-1}$ provided a lower average value of losses $\left(0.33 \mathrm{Mg} \mathrm{ha}^{-1}\right)$, when the 3520 
Table 1. Average results of the technological analysis of sugarcane at harvesting.

\begin{tabular}{ll}
\hline Characteristics of sugarcane crop & \\
\hline Estimated yield $\left(\mathrm{Mg} \mathrm{ha}^{-1}\right)$ & 95.0 \\
Average length of stems $\left(\mathrm{m}^{-1}\right)$ & 2.3 \\
Stem diameter (mm) & 20.1 \\
Cultivation time (months) & 13.0 \\
Maturation degree (\%) & TRS: 12.3 ; Purity: 83.8 and Fiber: 12.0 \\
\hline Note: TRS = Total Recoverable Sugars.
\end{tabular}
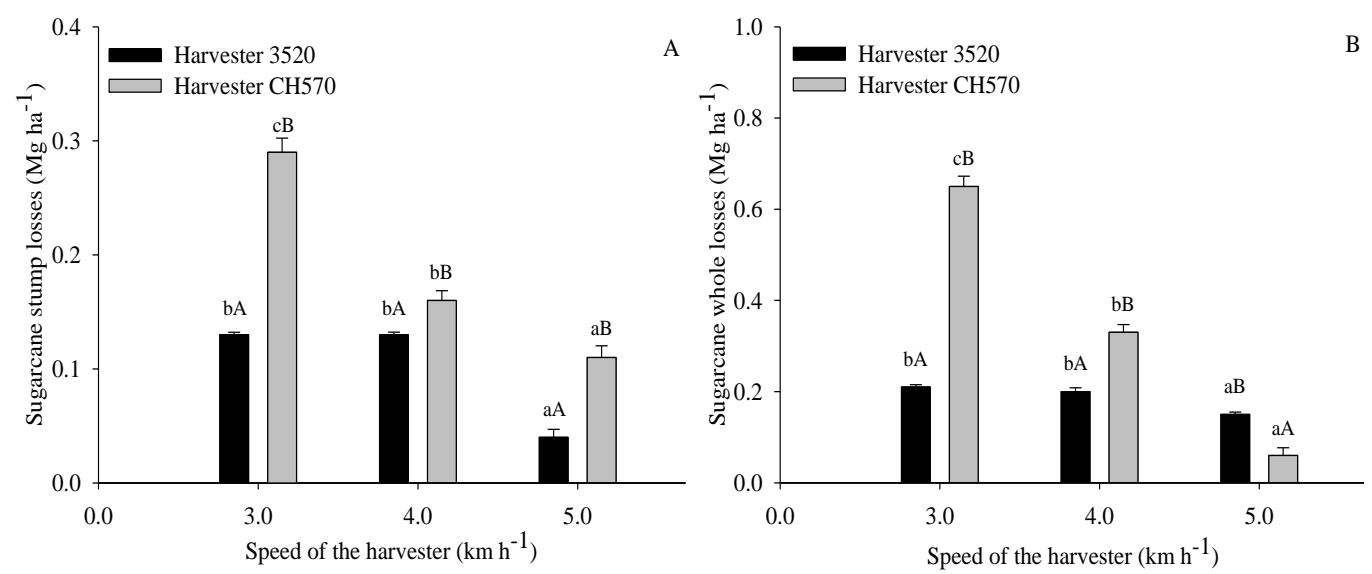

Fig 1. Sugarcane stump losses (A) and sugarcane whole losses (B) as a function of the speed of displacement of two harvester models in the Southwestern region of Goiás, Brazil. Means followed by the same lowercases letters indicate nonsignificant differences for displacement speed at the $5 \%$ level by Tukey's test. Means followed by the same capital letters indicate nonsignificant differences for the harvesters at the $5 \%$ level by Tukey's test.F-test = significant interaction at 0.01 probability; CV $(\%)=14.13(\mathrm{~A})$ and $11.04(\mathrm{~B})$

Table 2. Chemical characteristics of the soil from the experimental area in the Southwestern of Goiás, Brazil.

\begin{tabular}{|c|c|c|c|c|c|c|c|c|c|c|c|}
\hline Depth & $\mathrm{pH}$ & $\mathrm{OM}$ & $P$ & $\mathrm{~V}$ & $S$ & $\mathrm{~K}$ & $\mathrm{Ca}$ & $\mathrm{Mg}$ & $\mathrm{H}+\mathrm{Al}$ & SB & CEC \\
\hline $\mathrm{m}$ & $\mathrm{CaCl}_{2}$ & $\begin{array}{l}\mathrm{g} \\
\mathrm{dm}^{-3}\end{array}$ & ${ }_{3}^{\mathrm{mg} d m}$ & $\%$ & ----.. & --.--..- & 1 & & & & \\
\hline $0-0.25$ & 4.66 & 38.8 & 15.4 & 34.5 & 0.30 & 0.06 & 1.6 & 0.3 & 3.7 & 2.0 & 5.6 \\
\hline $0.25-0.50$ & 4.83 & 29.5 & 8.5 & 32.1 & 0.34 & 0.04 & 1.1 & 0.3 & 3.1 & 1.5 & 4.5 \\
\hline
\end{tabular}
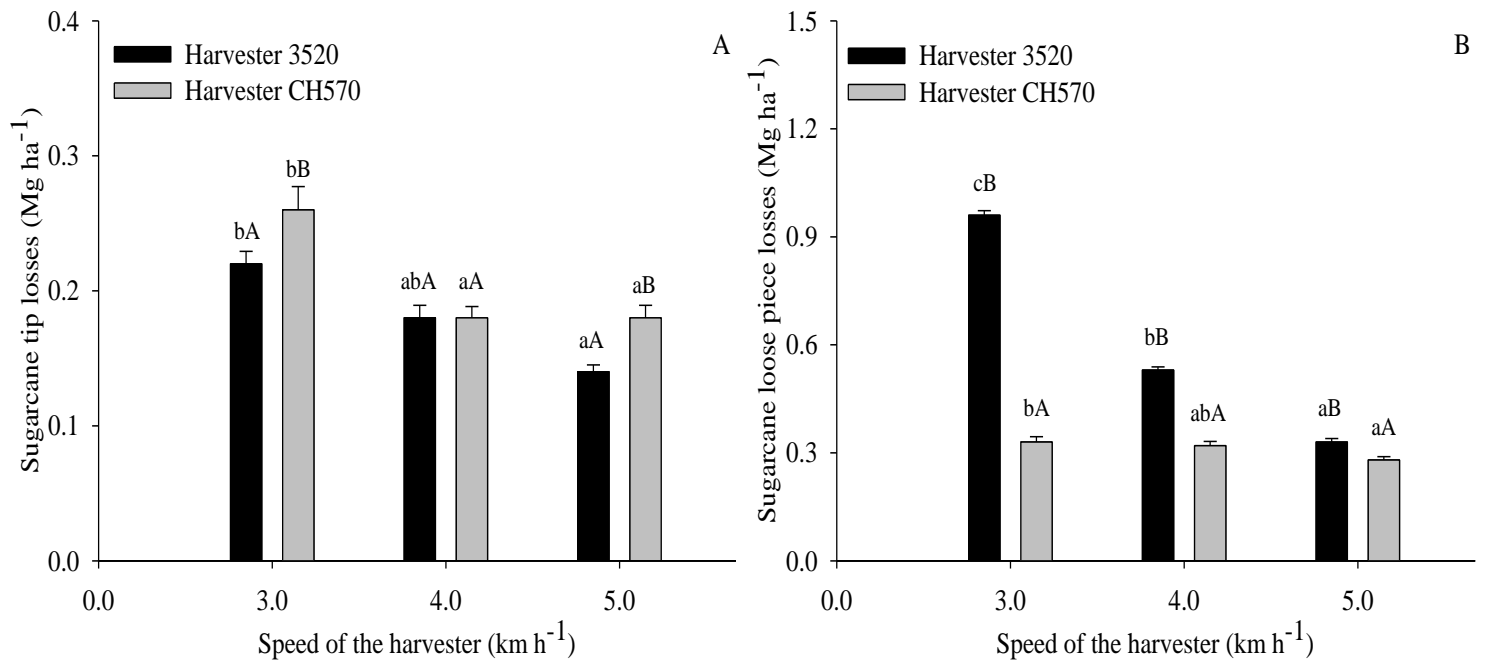

Fig 2. Sugarcane tip losses (A) and sugarcane loose piece losses (B) as a function of the speed of displacement of two harvester models in the Southwestern region of Goiás, Brazil. Means followed by the same lowercases letters indicate nonsignificant differences for displacement speed at the $5 \%$ level by Tukey's test. Means followed by the same capital letters indicate nonsignificant differences for the harvesters at the $5 \%$ level by Tukey's test. F-test = significant interaction at 0.05 probability; CV $(\%)=13.04(\mathrm{~A})$ and 15.08 (B) 

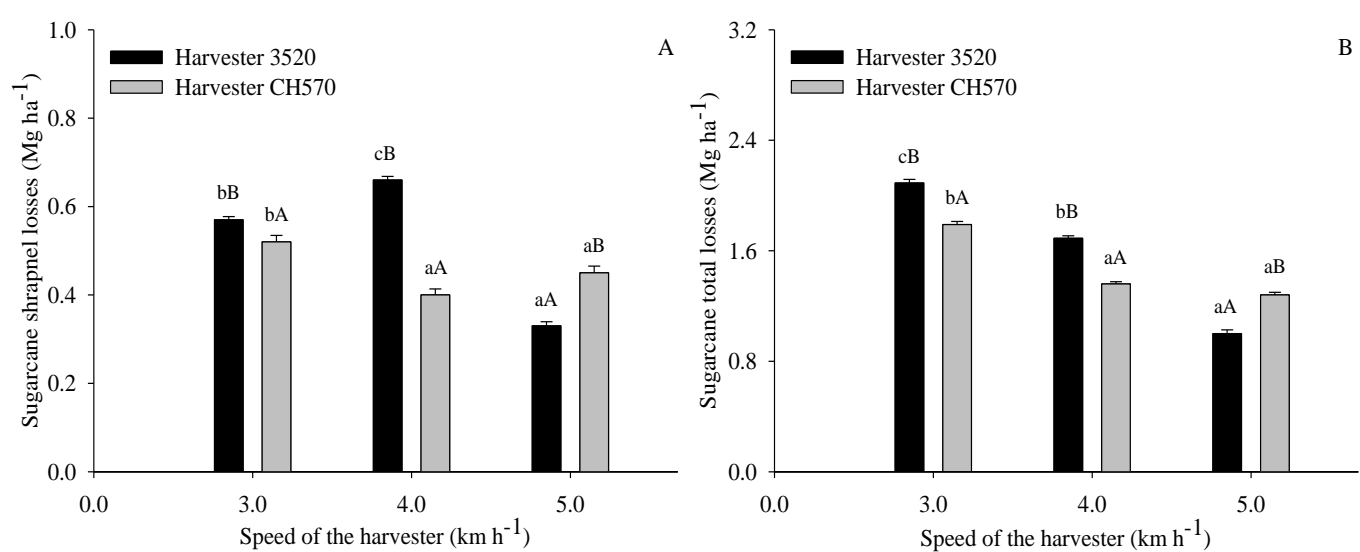

Fig 3. Sugarcane shrapnel losses (A) and sugarcane total losses (B) as a function of the speed of displacement of two harvester models in the Southwestern region of Goiás, Brazil. Means followed by the same lowercases letters indicate non-significant differences for displacement speed at the $5 \%$ level by Tukey's test. Means followed by the same capital letters indicate nonsignificant differences for the harvesters at the $5 \%$ level by Tukey's test. F-test $=$ significant interaction at 0.01 probability; $\mathrm{CV}$ $(\%)=12.84(\mathrm{~A})$ and $16.54(\mathrm{~B})$.
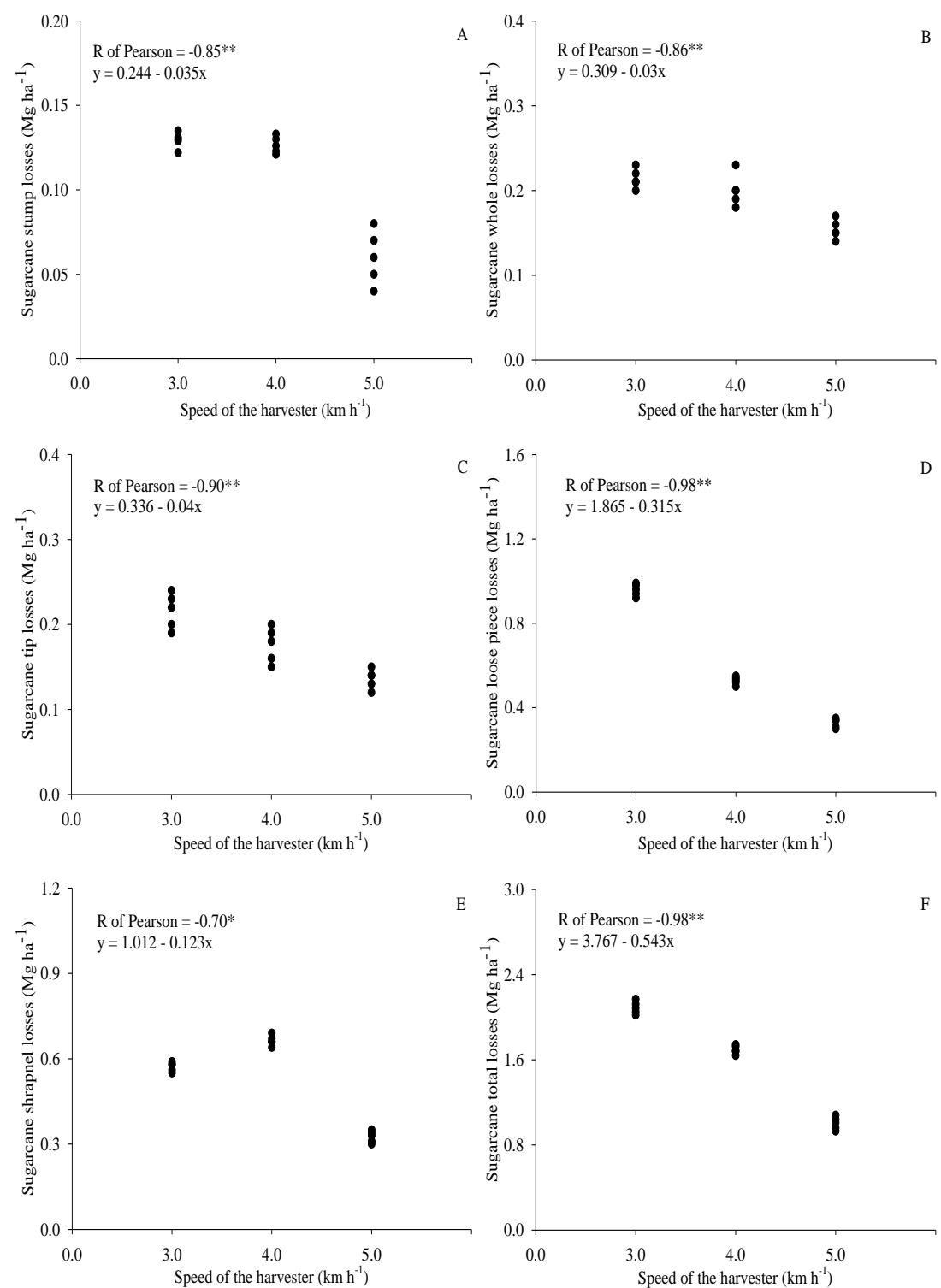

Fig 4. Data dispersion and Pearson correlation (R) between sugarcane stump losses (A), sugarcane whole losses (B), sugarcane tip losses $(C)$, sugarcane loose piece losses (D), sugarcane shrapnel losses (E) and sugarcane total losses (F) as a function of the displacement speed of the 3520 harvester in the Southwestern region of Goiás, Brazil. * significant at 0.05 probability; ${ }^{* *}$ significant at 0.01 probability 

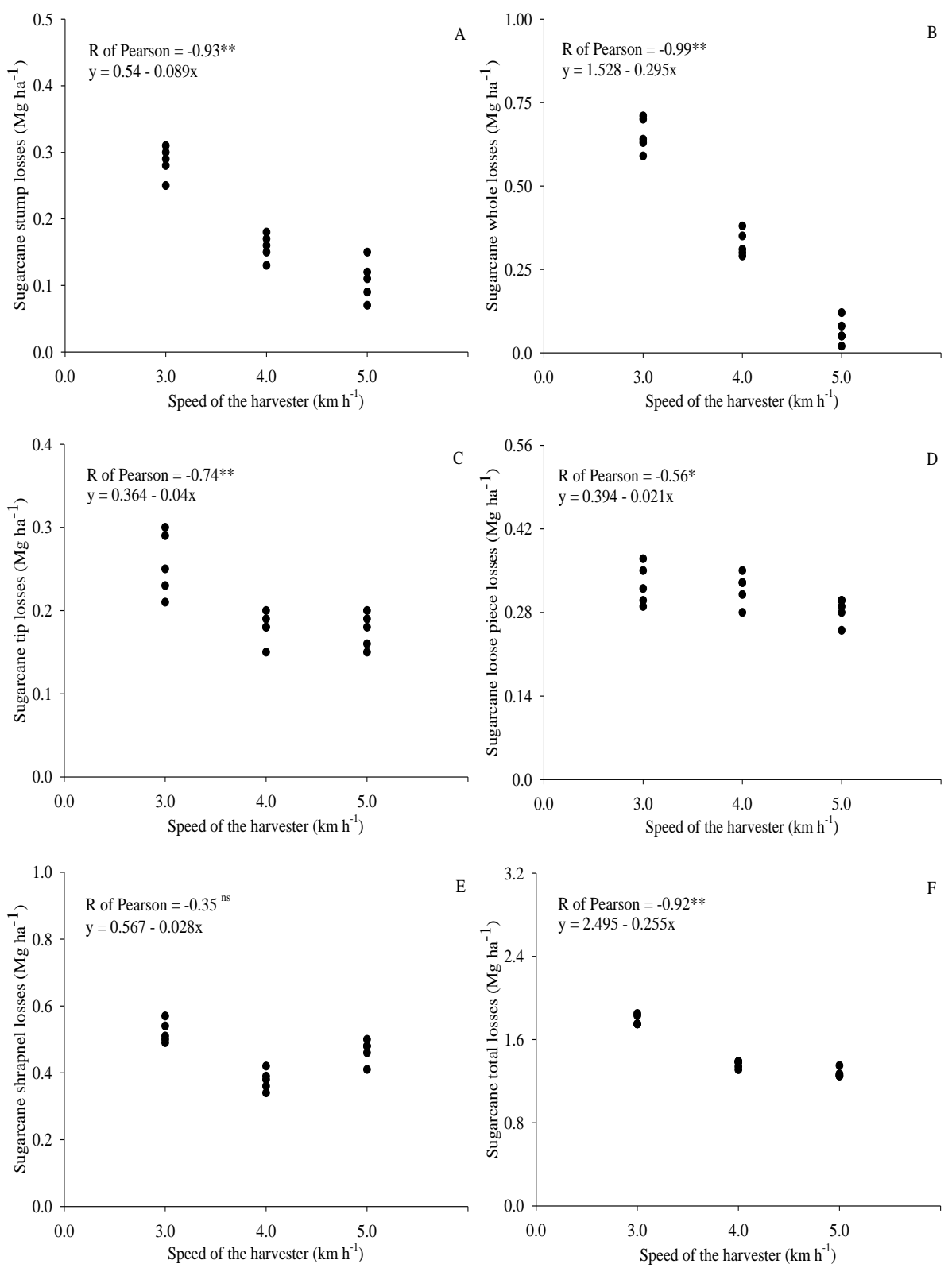

Fig 5. Data dispersion and Pearson correlation (R) between sugarcane stump losses (A), sugarcane whole losses (B), sugarcane tip losses (C), sugarcane loose piece losses (D), sugarcane shrapnel losses (E) and sugarcane total losses (F) as a function of the displacement speed of the $\mathrm{CH} 570$ harvester in the Southwestern region of Goiás, Brazil. *significant at 0.05 probability; ** significant at 0.01 probability; ${ }^{\text {ns }}$ not-significant.

harvester was operated. No significant differences were observed with the increase or reduction of the displacement speed in the $\mathrm{CH} 570$ harvester, which presented an average value of $0.31 \mathrm{Mg} \mathrm{ha}^{-1}$ of losses on the response variable (Fig 2B). Corroborating the results obtained in the $\mathrm{CH} 570$ harvester, Carvalho (2009), analyzed the visible losses of sugarcane in the field and observed that the loss indexes in the form of loose piece were not influenced by the increase of the speed of displacement of the harvester. Salvi (2006) also reported that increased loose piece loss may be related to other factors such as the failure of synchronization between harvester and trans-shipment, elevator floor wear, elevator flap damaged or misadjusted and overload in harvester's bowl. According to Moraes and Neves (1997), as the efficiency of cleaning of the extractors is increased the possibility of greater losses in the form of loose piece becomes higher, which is their speed of rotation. High-speed air flow, usually of the primary extractor, causes the suction of the sugarcane loose pieces that are later released in the field. On the other hand, the low performance of the 3520 harvester which is expressed by high raw material loss rates $\left(0.96 \mathrm{Mg} \mathrm{ha}^{-1}\right)$, may be associated with the lower harvester's displacement speed $\left(3.0 \mathrm{~km} \mathrm{~h}^{-1}\right)$. This contributes $\sim 45.9 \%$ to the increase in the percentage of total visible losses.

However, the present study obtained results, in which the losses varied in a way proportional to the decrease of the 
displacement speed and the model of the harvester. Corroborating the aforementioned results, the variable Sugarcane Shrapnel Losses (SShL) showed a significant difference between the displacement speeds and the harvester models tested in the operation. The use of the 3520 harvester at a speed of $5.0 \mathrm{~km} \mathrm{~h}^{-1}$ provided the lowest loss value and the best performance among harvesters, with an average of $0.33 \mathrm{Mg} \mathrm{ha}{ }^{-1}$ of SShL. The $\mathrm{CH} 570$ harvester achieved the best performance at speeds over $3.0 \mathrm{~km} \mathrm{~h}^{-1}$ (Fig 3A).

Pelloso et al. (2019), reported that the results of shrapnel losses are mainly influenced by the rotation speed of the primary extractor. Neves et al. (2004) confirmed that losses in the form of cane shrapnel usually occur due to the influence of the rotation speed of the primary extractor. According to these authors, as the rotation of the primary extractor increases, the loose pieces are sucked together with the straw and the soil. They are thrown on the field. When they pass through the extractor hoods they collide with the extractor blades, being torn in shrapnel and pieces, contributing to the increase of the losses.

However, the results obtained on this variable identified that the reduction of the displacement speed influenced the increase of the SShL, mainly in the 3520 harvester. The aforementioned results can help identification and elimination of the causes existing in the system, improving the operational quality through corrective actions, which can be applied before or during the operation, depending on the origin of the causes.

Neves et al. (2006) stated that factors such as the cutting stage, cane status (crooked or straight), spacing, harvester model, speed of displacement and primary extractor speed, have a great influence on the visible losses. However, the frequent evaluation of SSL, SWL, STL, SLPL, and SShL allows verifying if the sugarcane industry standards are being maintained to meet operational quality.

Neves et al. (2004) established a classification that considers the total visible losses as high $(>4.5 \%)$, average $(2.5<4.5 \%)$ and low $(<2.5 \%)$ in the sugarcane mechanized harvesting. Segato and Daher (2011) suggested that total losses close to 3.0 $\mathrm{Mg} \mathrm{ha}{ }^{-1}$ in the harvesting are considered acceptable by the sugarcane plants.

However, the Sugarcane Total Losses (SToL) observed in this study did not exceed the upper limit of the low interpretation class, with losses estimated of $2.09 \mathrm{Mg} \mathrm{ha}^{-1}$. In percentage loss data the treatments were characterized as low according to that proposed by the Sugarcane Technology Center (STC), which classified losses of less than 2.5\% (Benedini et al., 2009). Therefore, the low occurrence of SToL can be explained by the uniformity of the terrain, the periodic maintenance of the machines and the way the driver of the harvester handles it.

Regarding the causes of the variation between the treatments, these obtained a significant and proportional response to the decrease of the harvester's displacement speed. The best result was obtained with the 3520 harvester, with greater efficiency over this variable operating at a displacement speed of $5.0 \mathrm{~km} \mathrm{~h}^{-1}$, with mean SToL values of $1.00 \mathrm{Mg} \mathrm{ha}^{-1}$ (Fig 3B).

Similar results were presented by Manhães et al. (2014), in which the speed of $5.0 \mathrm{~km} \mathrm{~h}^{-1}$ obtained values between 0.94 and $1.62 \mathrm{Mg} \mathrm{ha}^{-1}$ of total losses.
The SToL data also showed that a displacement speed of less than $3.0 \mathrm{~km} \mathrm{~h}^{-1}$ leads to a significant increase of 47.8 and $28.5 \%$, when compared to the losses obtained at the highest displacement speed $\left(5.0 \mathrm{~km} \mathrm{~h}^{-1}\right)$ with the 3520 harvester and the $\mathrm{CH} 570$ harvester, respectively. In general, the displacement speed of $3.0 \mathrm{~km} \mathrm{~h}^{-1}$ resulted in greater visible losses for most of the parameters evaluated in this study such as SSL, SWL, STL, SLPL and SToL, while at higher speeds, there was a significant decrease in the loss index.

\section{Correlation between harvesting losses and displacement speed}

Correlation analysis showed the relationship between the sugarcane loss variables in the different displacement speeds of the two harvester models (Figs 4 and 5). The high correlations between these variables are of great importance for the characterization of the losses of raw material in the field, allowing decision making to correct or minimize possible losses in the mechanized harvesting in future crops without compromising crop production.

The correlation analysis between the determinations of sugarcane losses at different speeds of the 3520 harvester showed a strong negative correlation $(>0.70)$ for all evaluated parameters: SSL, SWL, STL, SLPL, SShL and SToL (Fig 4).

In this way, the negative linear relationship between the reduction of the losses with increase of the 3520 harvester displacement speed can be a good indicator when it is intended to define the best speed in the harvesting of sugarcane. These relations showed very strong correlations with the estimation of losses for some parameters, with coefficients of determination above 0.90 . Therefore, these losses were directly related to the harvester's displacement speed and can be considered relevant for reducing the production cost of sugarcane.

Similarly, the correlation analysis showed good concordances between the reduction of the visible losses in the sugarcane harvesting and the increase of the displacement speed for the $\mathrm{CH} 570$ harvester. The significant adjustments showed that the increase in the displacement speed $\left(5.0 \mathrm{~km} \mathrm{~h}^{-1}\right)$ promoted lower rates of sugarcane losses for the parameters: SSL, SWL, STL, SLPL and SToL, which showed determination coefficients of $-0.93,-0.99,-0.74$, 0.56 and -0.92 , respectively (Fig 5).

The negative linear behavior indicates that, as the $\mathrm{CH} 570$ harvester displacement speed increases, the loss index in the sugarcane harvesting decreases proportionally. The high correlation between these variables is of great importance for the diagnosis of production losses in field, which allows decision making to mitigate eventual future losses in the sugarcane harvesting, without compromising final production.

In this context, the data obtained in the present work are innovative and certainly can compose the database for calibration of the displacement speed, as well as the most efficient harvester model for the sugarcane crop. Obtaining more conclusive information on the displacement speed will certainly contribute to the production of crops, reduced losses, increased technical productivity and, above all, increased production efficiency. 


\section{Experimental area}

The experiment was carried out in an experimental area of the Usina BP Bioenergia Tropical S/A, in Edéia - GO, Brazil

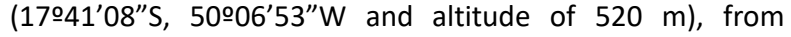
November 2017 up to September 2018. According to the Köppen classification, the regional climate is a Tropical Savanna (AW) with dry winter and rainy summer, with an annual rainfall of $1,423 \mathrm{~mm}$. The soil of the experimental area is classified as Rhodic Hapludox (USDA-Soil Survey Staff, 2010). For the chemical characterization of the soil samples were collected from the layers 0-0.25 and 0.25-0.50 m depth (Table 2). The evaluation area was a homogeneous plot of land, approximately $15 \mathrm{ha}^{-1}$, presenting clay soil (65\%) with an average slope of $3.0 \%$, characteristics considered adequate for mechanized harvesting.

\section{Plant materials}

The variety harvested was CTC4 of the Sugarcane Technology Center (STC), first cut (cane plant), with spacing between lines of $1.5 \mathrm{~m}$ and upright growing. The total average productivity of the area was $95.0 \mathrm{Mg} \mathrm{ha}{ }^{-1}$. The sugarcane harvesting operation was carried out 45 days after the application of MODDUS ${ }^{\circ}$ growth regulator by Syngenta, without prior burning of the straw.

\section{Experimental design and procedure}

The experimental design was completely randomized in a $2 \mathrm{x}$ 3 factorial scheme with five replications, totaling 30 plots. The loss survey was carried out in each plot of land with the aid of a metal frame of $45 \mathrm{~m}^{2}$, left in the three central lines $(4.5 \times 10 \mathrm{~m})$. The treatments consisted of two harvester models (John Deere 3520 and John Deere CH570), operated in three different displacement speeds $\left(3.0 \mathrm{~km} \mathrm{~h}^{-1}, 4.0 \mathrm{~km} \mathrm{~h}^{-1}\right.$ and $5.0 \mathrm{~km} \mathrm{~h}^{-1}$ ) in sugarcane harvesting, with base cutting pressure of $600 \mathrm{Psi}$ and rotation speed of the primary extractor between 800 and $900 \mathrm{rpm}$. The harvesters operated on the cane field with a John Deere $4 \times 2$ TDA (front-wheel drive) tractor with 225 horsepower, coupled to the transshipment with a capacity of $20 \mathrm{Mg}$, at a constant displacement speed, similar to the harvester.

\section{Biometric evaluations}

The material was collected, classified and later weighed in a semi-analytical balance, following the methodology described by Reis (2009). The quality indicators assessed after sugarcane harvesting were the following loss types: stump cane, whole cane, tip cane, loose piece cane, shrapnel cane and total cane loss in $\mathrm{Mg} \mathrm{ha}{ }^{-1}$.

\section{Statistical analysis}

The data were submitted to analysis of variance and to the F-test and the means were compared by the Tukey's test at a $5 \%$ probability level. Pearson's correlation $(p<0.05)$ between the harvester's displacement speed and the visible losses in the sugarcane harvesting was also evaluated, using the Sisvar program, Brazil (Ferreira, 2014).
In the field conditions presented, the increase of the displacement speed resulted in lower total losses in the sugarcane harvesting. The 3520 harvester was superior to the $\mathrm{CH} 570$ harvester at the highest speed tested. The reduction of sugarcane harvesting loss indexes was proportional to the increase of the displacement speeds for the parameters: sugarcane stump losses, sugarcane whole losses, sugarcane tip losses, sugarcane loose piece losses, and sugarcane total losses, for 3520 harvester and sugarcane stump losses, sugarcane whole losses and sugarcane total losses for $\mathrm{CH} 570$ harvester, which showed a strong negative correlation $(>0.85)$.

\section{Acknowledgments}

We thank to Usina BP Bioenergia Tropical S/A company for the total logistical and operational support; to the Coordination for the Improvement of Higher Education Personnel (CAPES) for the granting of a scholarship to the 1st author, and the FAPEG - Goiás Research Foundation for the financial support in the translation and publishing processes of the paper.

\section{References}

Benedini MS, Brod FPR, Perticarrari JG (2009) Sugarcane losses and plant and mineral impurities in mechanized harvesting. Sugarcane Technology Center - STC. (Technical Circular).

Carvalho Filho SM (2000) Mechanized harvest: operational and economic performance in sugarcane without previous burning. M.Sci. Thesis. Universidade Estadual Paulista, Brazil.

Carvalho LS (2009) Operational performance of a harvester in green cane in the area of Grande Dourados-MS. M.Sci. Thesis. Universidade Federal da Grande Dourados, Brazil.

Conab (2018) Follow-up of the Brazilian Crop: sugarcane 2017/18. Fourth Survey. 4(4):23-25.

Dias de Moraes MAF (2007) Indicators of the labor market of the Brazilian sugarcane agroindustrial system in the period of 1992-2005. Estud Econ. 37(4):875-902.

Ferreira DF (2014) Sisvar: a guide for its bootstrap procedures in multiple comparisons. Cienc Agrotec. 38(2): 109-112.

Furlani Neto VL, Ripoli TCC, Villa Nova NA (1996) Mechanical harvest: losses of raw material in cane fields with and without previous burning. STAB - Álcool, Açúc e Subprod. 14:19-23.

Maleki HMG and Jamshidi A (2011) Forecast model of sugar loss due to mechanical harvesting of the sugarcane crop. Aust J Basic Appl Sci. 5(12): 1190-1194.

Manhães CMC, Garcia RF, Correa Júnior D, Francelino FMA, Francelino HO, Santos CMG (2014) Evaluation of visible losses and damage to the ratoon cane in the mechanized harvesting of sugarcane for different displacement speeds. Am J Plant Sci. 5(20): 2956-2964.

Martins MB, Ramos CRG, Souza FL, Sartori MMP, Lanças KP (2017) Relationship between harvester speed, sugarcane yield and fuel consumption of harvester. Rev Agricul Neotrop. 4(1):88-91. 
Martins MB, Testa JVP, Drudi FS, Sandi J, Ramos CRG, Lanças KP (2019) Interference of speed at cutting height and damage to rootstock in mechanical harvesting of sugarcane. Aust J Crop Sci. 13(08):1305-1308.

Moraes EE, Neves JLM (1997) Raw cane harvest: evaluation of invisible losses in systems with chopped cane harvesters. In: Seminar on Agronomic Technology. Anais... 7:288-297.

Neves JLM, Magalhães PSG, Ota WM (2004) Sugarcane loss monitor, adapted to a commercial chopper sugarcane harvester. Eng Agric. 24(3):764-770.

Neves JLM, Magalhães PSG, Moraes EE, Araújo FVM (2006) Evaluation of invisible losses in mechanical harvesting in two sugarcane mass flows. Eng Agric. 26(3):787-794.

Pancelli MA, Prado RM, Flores RA, Almeida HJ, Moda LR, Souza Junior JP (2015) Growth, yield and nutrition of sugarcane ratoon as affected by potassium in a mechanized harvesting system. Aust J Crop Sci. 9:915-924.

Peloia PR, Milan M, Romanelli TL (2010) Capacity of the mechanical harvesting process of sugarcane billets. Sci Agric. 67(6):619-623.

Pelloso MF, Lima AA, Pelloso BF, Silva AP (2019) Losses on the mechanized harvesting of sugarcane in response to different harvester speeds and rotation of primary extractor. Colloq Agrar. 15:114-120.

Reis GN (2009) Losses in the mechanized harvesting of raw sugar-cane due to wear on cutting base blades. Ph.D Thesis. Universidade Estadual Paulista, Brazil.
Ripoli TCC, Carvalho Filho SM, Molina Júnior WF, Ripoli MLC (2001) Economic performance of harvester in raw cane. Eng Rural. 12:1-5.

Ripoli TCC, Ripoli MLC (2005) Biomass of sugarcane: harvesting, energy and environment. 2.ed. Piracicaba: The Authors, p. 320.

Ripoli TCC, Ripoli MLC (2009) Biomass of sugarcane: harvesting, energy and environment. 2.ed. Piracicaba: The Authors, p. 333.

Rodrigues EB, Saab OJGA (2007) Technical and economical evaluation of hand and mechanized harvest of sugarcane (saccharum spp) in Bandeirantes - Pr. Semin-Cienc Agrar. 28(4):581-588.

Salvi JV (2006) Base cutting quality of sugarcane harvesters. M.Sci. Thesis. Universidade Estadual Paulista, Brazil.

Salvi JS, Matos MA, Milan, M (2007) Evaluation of the performance of a base cutting device of a sugarcane harvester. Eng Agric. 27(1):201-209.

Segato SV, Daher F (2011) Visible losses in mechanized harvesting of raw sugarcane under harvester displacement speeds. Nucleus. 8: 315-326.

Silva RC, Oliveira TC, Figueiredo ZN, Caldeira DAS (2015) Visible losses in mechanized harvesting of sugarcane in the southwest region of Mato Grosso. Eng Agric. 23(1): 12-25.

Usda - Soil Survey Staff. 2010. Keys to Soil Taxonomy. Washington DC, USA. 10: 241-256.

Voltarelli MA, Silva RP, Rosalen DL, Zerbato C, Cassia MT (2013) Quality of performance of the operation of sugarcane mechanized planting in day and night shifts. Aust J Crop Sci. 7(9):1396-1406. 